\title{
Transient Osteoporosis of the Hip in a Middle-Aged Male Construction Worker
}

TIMOTHY S.H. KWOK, Student, Faculty of Medicine, University of Ottawa, Ottawa; THANU NADARAJAH RUBAN, MD, FRCPC, Staff Rheumatologist, Department of Medicine, Markham Stouffville Hospital, Markham; MICHAEL STEIRMAN, MD, FRCPC, Staff Radiologist, Department of Radiology, Markham Stouffville Hospital, Markham, Ontario, Canada. Address correspondence to Mr. T. Kwok, Faculty of Medicine, University of Ottawa, Roger Guindon Hall, 451 Smyth Road, Room 2046, Ottawa, Ontario K1H 8M5, Canada. E-mail: Timothy.Kwok@uottawa.ca. J Rheumatol 2017;44:258; doi:10.3899/jrheum.160934

Transient osteoporosis of the hip (TOH) is an underdiagnosed idiopathic condition mostly affecting healthy middle-aged men and pregnant women, with the presence of functional disability out of proportion to clinical examination ${ }^{1}$. Magnetic resonance imaging (MRI) features sharply demarcated femoral head bone marrow edema (BME) up to the intertrochanteric line without osteonecrotic signs or articular collapse $^{2}$.

A 54-year-old male construction worker presented with a 6-week history of right hip arthralgia upon weight-bearing. He was constitutionally well and a rheumatological review of systems was negative. On examination, stress pain was elicited along with restriction in right hip flexion and external and internal rotation. Radiograph of the right hip was unremarkable. An MRI of his right hip revealed elements suggestive of $\mathrm{TOH}$, including well-delineated edema in the femoral head and neck, a small joint effusion, and the absence of osteonecrotic signs or collapse of the femoral head (Figure 1). He was discharged home with acetaminophen as needed for analgesia. The patient was seen in followup 3 months later

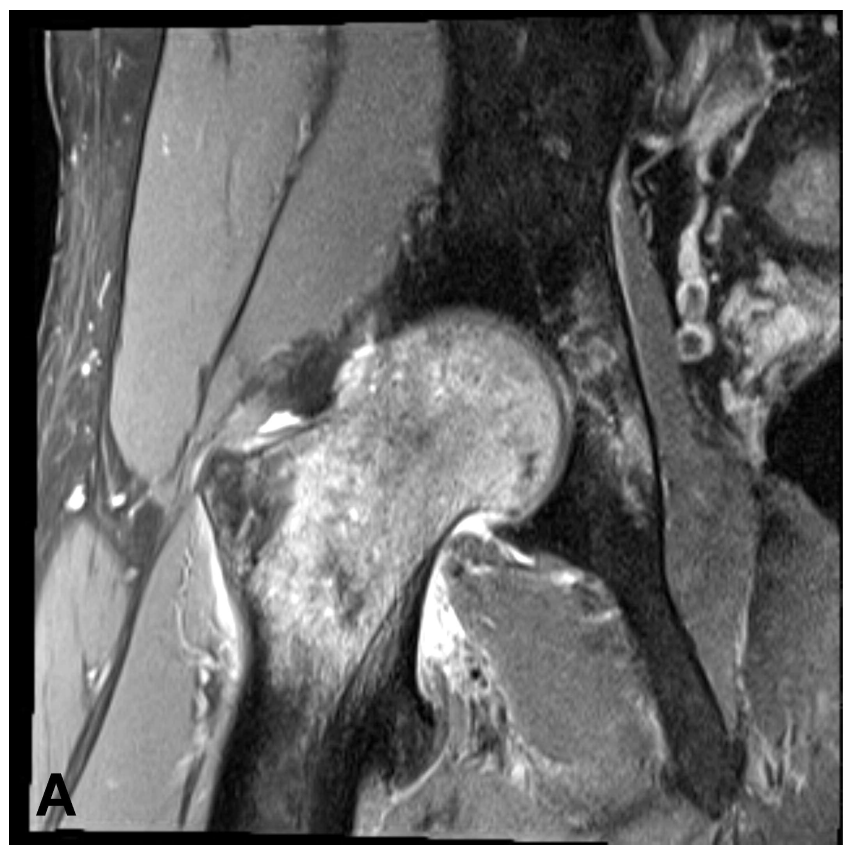

with marked improvement of his joint symptoms along with normal right hip range of motion (ROM).

The patient's occupation as a construction worker initially placed a diagnosis of soft tissue injury higher on the differential. However, given persistence of arthralgia symptoms along with restriction in ROM, primary joint etiology was suspected. Clinically, normal radiographic and MRI findings are hallmarks of TOH. Further, the self-resolving characteristic of this condition excluded the presence of more insidious causes of BME such as avascular necrosis ${ }^{3}$.

\section{REFERENCES}

1. Bijl M, van Leeuwen MA, van Rijswijk MH. Transient osteoporosis of the hip: presentation of (a)typical cases and a review of the literature. Clin Exp Rheumatol 1999;17:601-4.

2. Klontzas ME, Vassalou EE, Zibis AH, Bintoudi AS, Karantanas AH MR imaging of transient osteoporosis of the hip: an update on 155 hip joints. Eur J Radiol 2015;84:431-6.

3. Rocchietti March M, Tovaglia V, Meo A, Pisani D, Tovaglia P, Aliberti G. Transient osteoporosis of the hip. Hip Int 2010; 20:297-300.

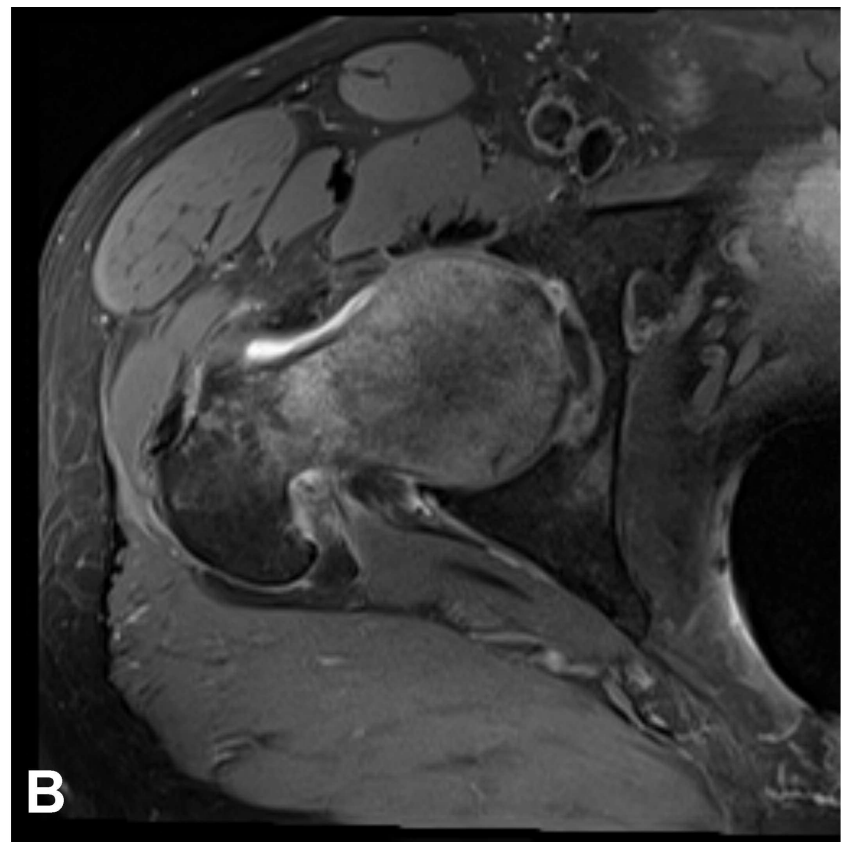

Figure 1. Coronal (A) and axial (B) T2 fat-saturated magnetic resonance images of the right hip revealed extensive marrow edema in the femoral head and neck. Mild edema in the medial acetabulum and a small joint effusion can also be seen.

Personal non-commercial use only. The Journal of Rheumatology Copyright $@$ 2017. All rights reserved 